\title{
Chapter 14 \\ Contamination Levels of Radioactive Cesium in Fat Greenling Caught at the Main Port of the Fukushima Dai-ichi Nuclear Power Plant
}

\author{
Ken Fujimoto, Shizuho Miki, and Tamaki Morita
}

\begin{abstract}
Levels of radioactive cesium (radiocesium, ${ }^{134} \mathrm{Cs}+{ }^{137} \mathrm{Cs}$ ) detected in fish caught at the Fukushima Dai-ichi Nuclear Power Plant (FNPP) Port are summarized. The mean concentration of radiocesium in three fish species (fat greenling, Japanese rockfish, and spotbelly rockfish) was significantly different from that in other fish species studied (brown hakeling, black rockfish, Japanese black porgy, olive flounder, marbled flounder). The levels of radiocesium in fat greenling decreased gradually from $100 \mathrm{kBq} / \mathrm{kg}$-wet in 2013 to several kBq/kg-wet in 2014 . A migration of fat greenling into the FNPP Port was assumed to explain the fact that fish containing low radiocesium levels were caught at the port. A low but significant correlation between the total length of the fish and the radiocesium concentration in the muscles was observed in fat greenling caught at the FNPP Port.
\end{abstract}

Keywords Radiocesium • Fat greenling • Japanese rockfish • Spotbelly rockfish • FNPP Port

\subsection{Introduction}

The Ministry of Agriculture, Forestry and Fisheries (MAFF), Fukushima Prefecture, and the Fisheries Research Agency (FRA) have been monitoring marine organisms to ensure the safety of fish and fishery products since 2011, immediately after the Fukushima Dai-ichi Nuclear Power Plant (FNPP) accident (MAFF 2013). Although about $40 \%$ of marine organisms collected from the area off the coast of Fukushima Prefecture within a year after the accident contained radiocesium $\left({ }^{134} \mathrm{Cs}+{ }^{137} \mathrm{Cs}\right)$ at levels exceeding the Japanese safety limit (100 Bq/kg-wet) (Buesseler 2012), the

K. Fujimoto $(\bowtie) \cdot \mathrm{S}$. Miki $\bullet$ T. Morita

National Research Institute of Fisheries Sciences, Fisheries Research Agency,

2-12-4, Fukuura, Kanazawa, Yokohama, Kanagawa 236-8648, Japan

e-mail: fujiken@affrc.go.jp 
percentage of samples containing radiocesium levels exceeding the allowable limit decreased to $1.9 \%$ by the end of 2013 (MAFF 2013). The contamination levels of radiocesium were gradually decreased even in fish caught in Fukushima Prefecture coastal waters (MAFF 2013). However, an extremely high concentration of radiocesium $(25,800 \mathrm{~Bq} / \mathrm{kg}$-wet) was detected in fat greenlings caught in the Ota River (20 km north of the FNPP) on August 1, 2012, as reported by the Tokyo Electric Power Company (TEPCO 2014).

In contrast to intensive monitoring of fishery products caught in offshore waters, data for the radionuclide contamination of fish at the FNPP Port were limited because sample collection from this area was difficult. Highly contaminated water was directly discharged from the reactors into the port of FNPP during the early period after the FNPP accident. TEPCO has been monitoring water quality at several stations at the FNPP Port daily, and the results are available on http://www. tepco.co.jp/en/nu/fukushima-np/f1/smp/index-e.html. TEPCO also conducted a Fish Contaminant Monitoring Program at the FNPP Port, and the results were published in 2014. However, the data were focused only on the levels of radiocesium in fish, whereas other related information (e.g., size of the fish) was not made available to the public.

In this section, we summarize the data released from TEPCO relating to radiocesium levels in eight fish species (fat greenling, Japanese rockfish, spotbelly rockfish, brown hakeling, black rockfish, Japanese black porgy, olive flounder, marbled flounder) caught at the FNPP Port, focused on the radiocesium concentration in the muscle tissues of fat greenling (Hexagrammos otakii).

In this study, the data of ${ }^{137} \mathrm{Cs}$ concentration in seawater and the concentration of radiocesium in the muscles of fish species caught at the FNPP Port were obtained from the TEPCO website (http://www.tepco.co.jp/en/nu/fukushima-np/f1/smp/ index-e.html). Fat greenling samples were collected using small cages and gill nets in a period from February 25, 2013 to May 16, 2014 by TEPCO (Fig. 14.1). After analyzing the data, TEPCO provided the samples to the National Research Institute of Fisheries Science (NRIFS) of FRA. The samples were stored at $-20{ }^{\circ} \mathrm{C}$ at the TEPCO laboratory near the Hirono Thermal Power Plant (21 km south of the FNPP) before shipment.

\subsection{Concentrations of Radiocesium in Seawater and Fish Caught at the Port of FNPP}

The concentration of ${ }^{137} \mathrm{Cs}$ in seawater at the unloading deck (station ULD in Fig. 14.1) steeply increased shortly after the beginning of discharge from the reactors. The maximum level of ${ }^{137} \mathrm{Cs}(660 \mathrm{kBq} / \mathrm{l})$ was detected on April 6, 2011. The level of ${ }^{137} \mathrm{Cs}$ rapidly decreased to $1 \mathrm{kBq} / \mathrm{l}$ at the end of April 2011 and to $100 \mathrm{~Bq} / \mathrm{l}$ in mid-June 2011 (Fig. 14.2). The concentration factor of ${ }^{137} \mathrm{Cs}$ in fish ranged between 5 and 100 (IAEA 2004). Considering the concentration factor, ${ }^{137} \mathrm{Cs}$ levels 


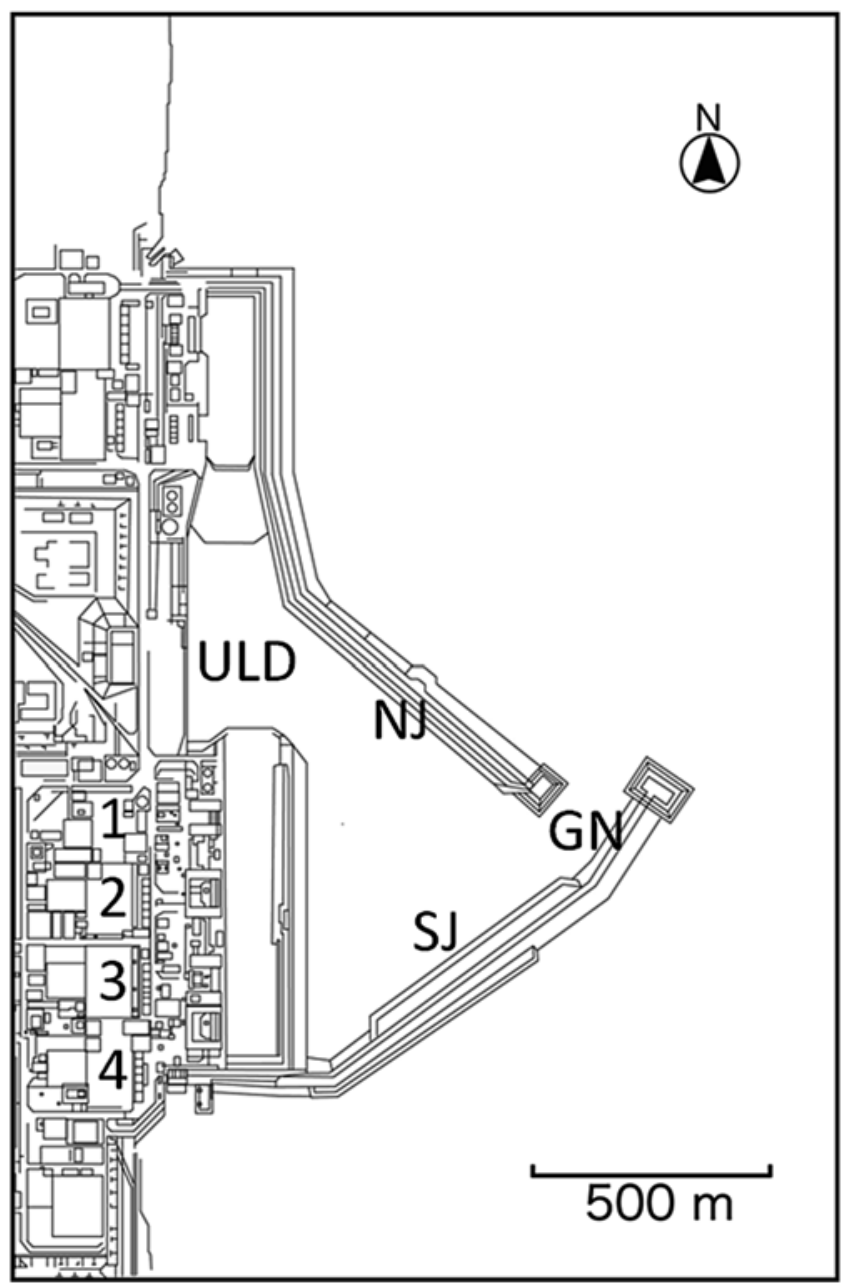

Fig. 14.1 Map of the monitoring sites at the Fukushima Dai-ichi Nuclear Power Plant (FNPP) and Port. 1-4 reactor units $1-4, U L D$ point of cage sampling at the unloading deck, $S J$ point of cage sampling at the north jetty, $N J$ point of cage sampling at the south jetty, $J N$ point of gill net sampling at the port entrance

in fish at the FNPP Port could have reached $1,000 \mathrm{kBq} / \mathrm{kg}$-wet between early and mid-April 2011 and 10 kBq/kg-wet in mid-June 2011.

Box plots shown in Fig. 14.3 illustrate the levels of radiocesium in the muscles of eight fish species caught at the FNPP Port. The average radiocesium concentrations of three species (fat greenling, Japanese rockfish, and spotbelly rockfish) were significantly different from those in the other five species (Fig. 14.3; $p<0.05$, Scheffe's test). The inter-quartile range of spotbelly rockfish and Japanese rockfish was narrower than that of fat greenling. Although the 75th quartiles of spotbelly 


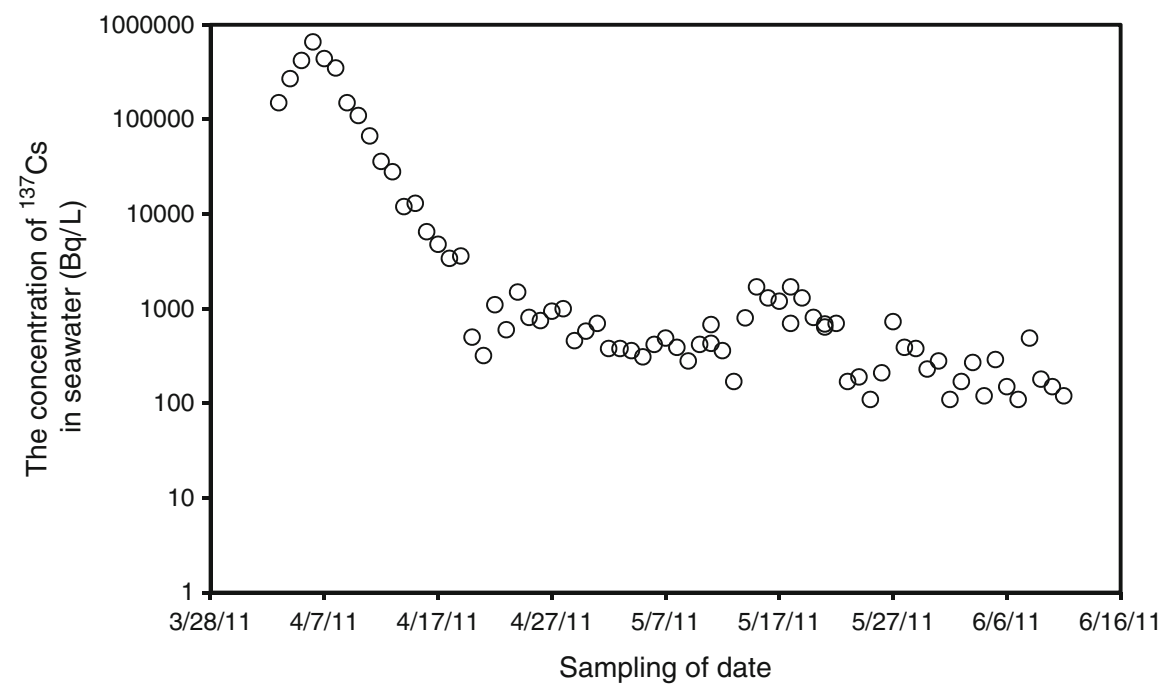

Fig. 14.2 Temporal changes in ${ }^{137} \mathrm{Cs}$ concentration in seawater samples collected at the unloading deck at the FNPP Port. Data were obtained from http://www.tepco.co.jp/en/nu/fukushima-np/f1/ smp/index-e.html

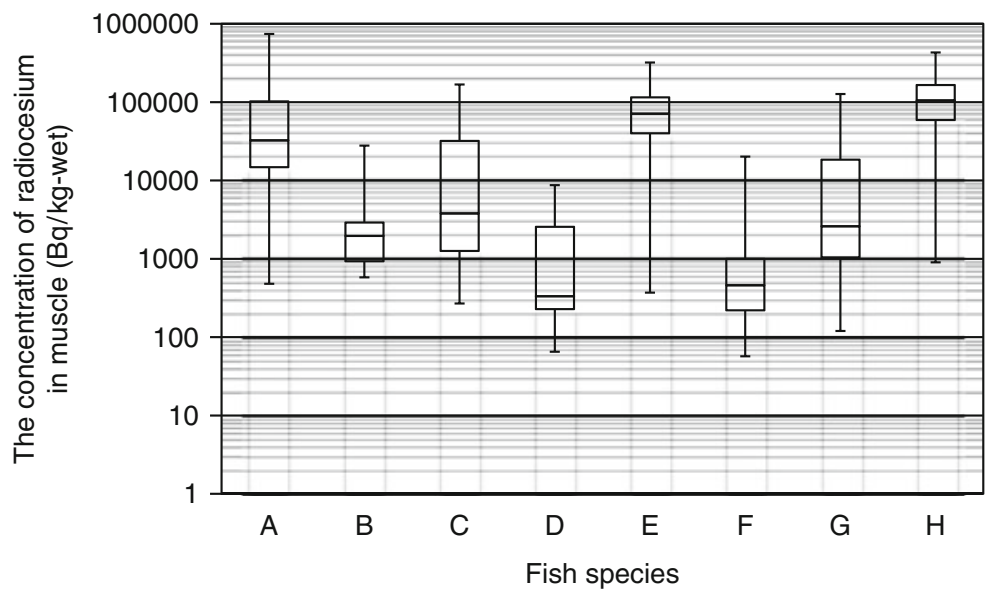

Fig. 14.3 Boxplots of radiocesium concentration in the muscles of fish caught at the FNPP Port from December 20, 2012 to November 19, 2013. Each box indicates the inter-quartile range. The line inside the box shows the median. The lines extending vertically from the boxes (whiskers) show the variability outside the quartiles. Fish species: $A$ fat greenling (Hexagrammos otakii), $B$ brown hakeling (Physiculus maximowiczi), C black rockfish (Sebastes schlegeli), D Japanese black porgy (Acanthopagrus schlegelii), E Japanese rockfish (Sebastes cheni), $F$ olive flounder (Paralichthys olivaceus), $G$ marbled flounder (Pleuronectes yokohamae), $H$ spotbelly rockfish (Sebastes pachycephalus) 
rockfish and Japanese rockfish were higher than $100 \mathrm{kBq} / \mathrm{kg}$-wet, the median of radiocesium concentration in black rockfish was less than $10 \mathrm{kBq} / \mathrm{kg}$-wet. Furthermore, the inter-quartile range of black rockfish was wider than that of the other two rockfish species, indicating that fluctuations in radiocesium levels in the black rockfish sample population were more intense than those observed in other rockfish. Interestingly, within the flatfish group, the mean radiocesium concentration in marbled flounder was significantly higher than that in olive flounder $(p<0.001$; Wilcoxon-Mann-Whitney test).

Differences in concentrations of radiocesium among the studied fish species could not be explained only by the changes in radiocesium concentration in seawater. In addition to the direct intake of contaminated water by osmosis via the gills, incorporation of radiocesium through the consumption of prey via the food web might cause variations in radiocesium levels in fish. For example, although the Japanese flounder and marbled flounder live in the same environment, the mean concentrations of radiocesium differ between these two species, probably because their feeding habits are quite different. Japanese flounder prefer fish, whereas marbled flounder prefer worms living on the seabed. Similar to fish, prey organisms (e.g., crustaceans and worms) were labeled with radiocesium at various concentrations. Hence, the kind and amount of prey consumed were key factors influencing the levels of radiocesium within and between fish species living in waters at the FNPP Port.

\subsection{Temporal Changes in Radiocesium Levels in Fat Greenling Caught at the FNPP Port}

Figure 14.4 shows the temporal changes in radiocesium levels in the muscle tissues of fat greenling caught at the FNPP Port in a period from February 25, 2013 to May 16, 2014. The decreasing trend of radiocesium concentrations confirmed that the fluctuations among individual fish were intense in 2014. The levels of radiocesium were $100 \mathrm{kBq} / \mathrm{kg}$-wet and several $\mathrm{kBq} / \mathrm{kg}$-wet at the beginning of 2013 and 2014 , respectively. The radiocesium levels in a fish sample collected between June 12 and August 2, 2013 ranged between 0.48 and $0.92 \mathrm{kBq} / \mathrm{kg}$-wet, and the mean value was significantly lower than that of other samples collected within the same period ( $p<0.005$; Student's $t$ test). Additionally, a fat greenling captured on February 3,2014 had a radiocesium concentration of $0.13 \mathrm{~Bq} / \mathrm{kg}$-wet, which was the lowest concentration compared to that in other fat greenling caught at the FNPP Port. Although an explanation of these low radiocesium levels could be that some fat greenling either escaped from contaminated seawater or did not consume organisms containing high concentrations of radiocesium, it is more likely that these fish migrated to the FNPP Port long after the accident. TEPCO constructed barriers made of gill nets at the entrance of the FNPP Port to prevent the escape of fish. However, these barriers were temporarily removed to allow ships to enter and exit 


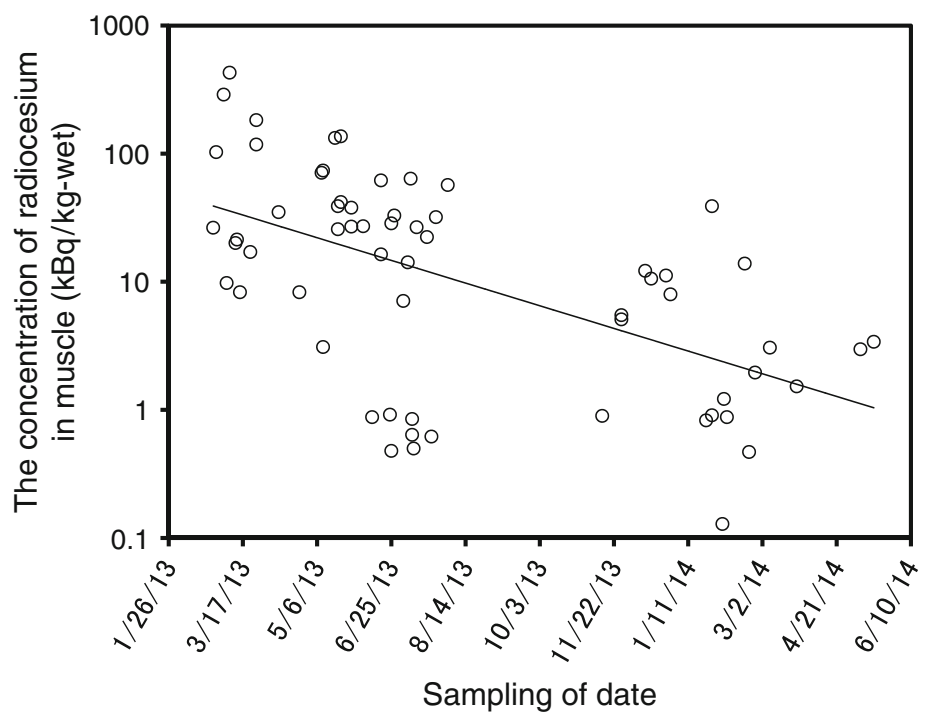

Fig. 14.4 Temporal changes in radiocesium concentration in fat greenling caught at the FNPP Port. Fish samples were collected from February 25, 2013 to May 16, 2014

the port. Therefore, the possibility of fat greenling migrating into the FNPP Port cannot be excluded. The concentration of ${ }^{137} \mathrm{Cs}$ in seawater sampled at the unloading deck (Fig. 14.1, ULD) was below 10 Bq/l in 2014 (TEPCO 2014). Taking into account the concentration factor, which ranged between 5 and 100 (IAEA 2004), ${ }^{137} \mathrm{Cs}$ levels in fat greenling that migrated into the FNPP Port would currently attain a maximum radiocesium concentration of $1 \mathrm{kBq} / \mathrm{kg}$-wet.

\subsection{Relationship Between Total Length and Radiocesium Level in the Muscles of Fat Greenling Caught at the FNPP Port}

A low but significant correlation $(r=0.395, p<0.005)$ between the total length and radiocesium concentration in the muscles was observed in fat greenling caught at the FNPP Port (Fig. 14.5). Because individuals caught within the experimental period were more than 3 years of age, as deduced from their total length (Fukushima Prefecture Fisheries Experimental Station 1974), all sampled fat greenling would have experienced an extremely high concentration of radiocesium in the seawater shortly after the accident (Fig. 14.2). The "size effect" reported for top fish species (Koulikov and Ryabov 1992) was also observed in fat greenling to some extent. Large-sized fat greenling (e.g., total length $>400 \mathrm{~mm}$ ) contained more radiocesium than did smaller ones because the former were 2 or more years of age and were able 


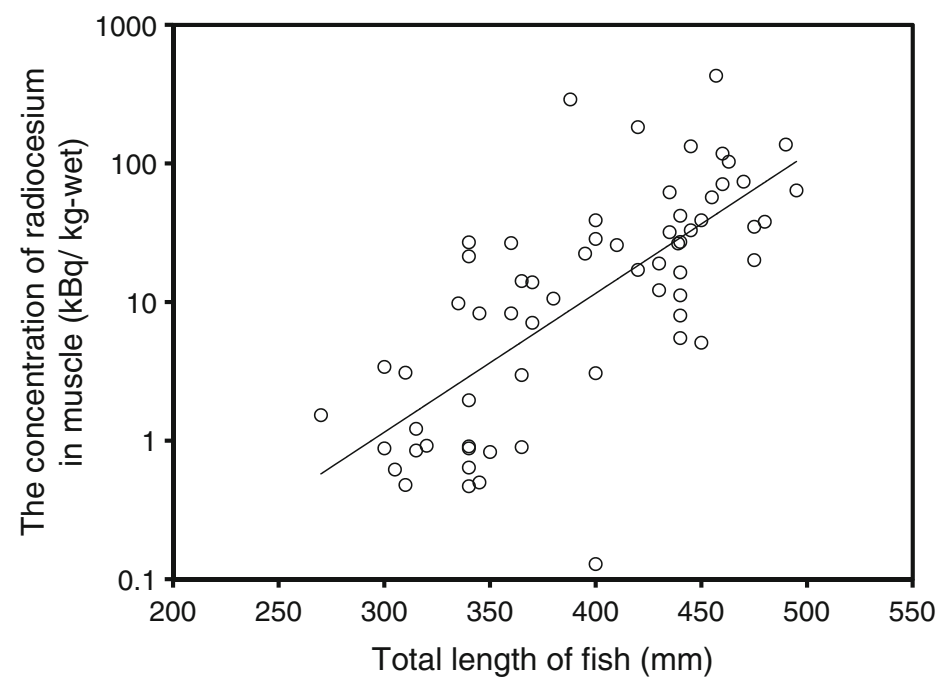

Fig. 14.5 Relationship between the total length of the fish and the concentration of radiocesium in muscles in fat greenling caught at the FNPP Port from February 25, 2013 to May 16, 2014

to catch prey at the time when extremely contaminated water was discharged into the FNPP Port. The amount of radiocesium that was once incorporated into the adult fish has been metabolized and excreted from the body; hence, the levels of radiocesium gradually decreased. In contrast, the concentration of radiocesium in young fish decreased more rapidly as the fish grew and the body mass increased. If the amount of radiocesium remains constant in the fish body, the concentration is reduced by half the initial value when the body mass of the fish doubles. The "growth effect" explains the low levels of radiocesium in small fat greenling (less than $300 \mathrm{~mm}$ during the sampling period) because they were very young in March 2011.

Acknowledgments We thank the staff of Tokyo Power Technology Co., Inc. for transporting the samples. This study was supported by the Fisheries Research Agency, Ministry of Agriculture, Forestry and Fisheries of Japan.

Open Access This chapter is distributed under the terms of the Creative Commons Attribution Noncommercial License, which permits any noncommercial use, distribution, and reproduction in any medium, provided the original author(s) and source are credited.

\section{References}

Buesseler KO (2012) Fishing for answers off Fukushima. Science 338:480-482

Fukushima Prefecture Fisheries Experimental Station (1974) Reports of stocks and habitat for selective fish living in fishing ground around northern part of the Pacific. No. 127 (in Japanese) 
International Atomic Energy Agency (IAEA) (2004) Sediment distribution coefficients and concentration factors for biota in the marine environment. Technical report series no. 422. International Atomic Energy Agency, Vienna, p 95

Koulikov AO, Ryabov IN (1992) Specific cesium activity in freshwater fish and the size effect. Sci Total Environ 112:125-142

Ministry of Agriculture, Forestry and Fisheries (MAFF) (2013) Results of the inspection on radioactivity level in fisheries products. http://www.jfa.maff.go.jp/e/inspection/. Accessed $15 \mathrm{Sept}$ 2014

Tokyo Electric Power Company (TEPCO) (2014) Results of radioactive analysis around Fukushima Daiichi Nuclear Power Station. http://www.tepco.co.jp/en/nu/fukushima-np/f1/smp/index-e. html. Accessed 15 Sept 2014 